\title{
Status of Female Literacy in Various Districts of Uttar Pradesh
}

\author{
Ansari, Shagufta Nazneen \\ Department of Education, Aligarh Muslim University, Aligarh \\ E-mail: Shagufta.nazneenamu@gmail.com \\ Nasreen, Nakhat \\ Department of Education, Aligarh Muslim University, Aligarh \\ E-mail: nakhat_nasreen@yahoo.co.in
}

Received: 08-02- 2013

Accepted: 20-03-2013

Published: 30-04-2014

doi:10.7575/aiac.ijels.v.2n.2p.24

URL: http://dx.doi.org/10.7575/aiac.ijels.v.2n.2p.24

\begin{abstract}
A population's literacy skills have a bearing on how well a country performs economically. Moreover, the education of women plays a significant role in improving living standards in the state. Improving girls' educational levels has been demonstrated to have clear impacts on the health and economic future of young women, which in turn improves the prospects of their entire community. The present study is conducted to explore the status of female literacy in various districts of Uttar Pradesh. The female literacy rate of all the districts have been categorized under five heads: 1. Very high, 2. High, 3. Average, 4.Low and 5. Very low. Female literacy rates were plotted on graph through monochromatic colour scheme to give a clear picture and understanding of female literacy. A very high regional variation with a declining trend regarding the female literacy was observed throughout the study area.
\end{abstract}

Keywords: female literacy, literacy trend, significance of female literacy

\section{Introduction}

A population's literacy skills have a bearing on how well a country performs economically. The world we live in today is vastly different from that of a generation ago. Technological change has transformed the way in which work is done; competition in many industries is global in nature; and the industrial structure of the Canadian labor market has rapidly evolved from a manufacturing and agricultural base to one based on services. These changes have, in turn, brought rising skill requirements. Countries that are successful in endowing their populations with strong skills are usually in a better position to meet the economic challenges of operating in a globalized information economy.

According to census 2011, "A person aged seven and above who can both read and write with understanding in any language is treated as literate. A person who can only read but cannot write is not literate".

Finally, having a population that has strong literacy skills also places a country in a better position to meet the complex social challenges that it faces. For example, strong literacy skills are linked to better health outcomes for individuals. A highly literate population will be better able to deal with issues of governance in a highly diverse society.

The female literacy situation in Uttar Pradesh is dismal at $42.98 \%$. However, the male literacy rate is reasonably better at $70.23 \%$. The overall literacy rate is still poor at $57.36 \%$ and much lower than the all India average. The State government has taken steps to make the population totally literate.

The education of women plays a significant role in improving living standards in the state. A higher women literacy rate improves the quality of life both at home and outside of home, by encouraging and promoting education of children, especially female children. Improving girls' educational levels has been demonstrated to have clear impacts on the health and economic future of young women, which in turn improves the prospects of their entire community.

\section{Rationale}

The topic related to female literacy rate is selected here because it is one of the important aspects for the upliftment and empowerment of women in any country. India being a country with high traditional values and developing in nature, strives to achieve a higher female literacy rate and education, so as to increase the status of women in the country.

Low female literacy rate means an overall sluggish growth of country, as it impacts every arena of the development. India is struggling hard to stabilize its growing population through family planning programs. But if females are illiterate, then this has a direct and negative impact on these initiatives.

When a girl or a woman is not educated, it is not only she who suffers but the entire family has to bear the consequences of her illiteracy. It has been found out that illiterate women face more hardships in life than literate ones. They have high levels of fertility as well as mortality; they suffer from malnutrition and all other related health problems. In one of the surveys, it has been found out that infant mortality is inversely related to mother's educational level. In such a scenario not only women but their kids also go through the same conditions. She, who does not know the importance of 
education in life, does not emphasize the same for her kids. This hampers the family as well as the nation's progress as a whole.

Lack of education, means lack of awareness. Illiterate women are not aware of their rights. They know nothing about initiatives taken by the government for their welfare. Illiterate women keep on struggling hard and bear harshness of life, family and even their husbands.

Females constitute about $50 \%$ of country's human resource but lack of education snatches their chance to be a part of the progress and development of India. This means our pace of progress is less than the required pace. Even if females do not use education to work, total illiteracy has a huge negative impact on our society.

There is a dramatic difference in the female literacy rate based on various regions in India and even within the state. Female literacy rate in urban areas is higher as compared to rural ones.

Bruke, F. (1983) had attempted to identify the geographical pattern of literacy levels of scheduled castes in Uttar Pradesh. She had observed that there were disparities in the literacy between rural-urban areas as well as in males and females within the district. Finally she concluded that backwardness and literacy are strongly correlated and literacy and socio-economic development go together.

Mathur, B.B. (1988) in his study of "spatial pattern of literacy in Uttar Pradesh" had observed that the extent of rural literacy show a wide disparity. He found that north hilly region, Ganga-Yamuna doab and some part of eastern plain show high rates of rural literacy whereas the larger part of eastern plain and the southern plateaus show low literacy rates.

Singh, U. K. and Singh, A. K. (2005) have analyzed the level of literacy among the Tharus of Mihinpurwa block of Bahraich district, Uttar Pradesh (India) and concluded that the level of literacy is very low among the Tharus in the studied block. The level of existing literacy was only up to primary stage. The study further shows that the level of literacy is higher in the village situated in the vicinity of Mihinpurwa town than that of the village situated in the remote areas. Poverty is the main cause of low literacy.

Tripathi, $\boldsymbol{R}$. S. (1993) had conducted a research on "Impact of urbanization on literacy and concentration of nonagricultural workers in rural areas of Bundelkhand (Uttar Pradesh)" and has examined the situation of literacy and the concentration of non-agricultural workers in rural areas of Bundelkhand with particular reference to the urbanization. He concluded that the higher degree of urbanization results in the higher level of literacy in rural areas and vice-versa.

Zaidi, A. N. (1986) had intended to analyze the disparities in educational development in different regions in India and particularly in various regions of the state of Uttar Pradesh on the basis of certain indicators of educational development. His study had pointed out the inter-state as well as the intra state inequalities in educational development.

\section{Objectives}

The present research paper aims at:

\subsection{Studying female literacy in various districts of Uttar Pradesh.}

3.2. Finding out the districts with high and low female literacy in the state.

3.3. Finding out a pattern of female literacy in Uttar Pradesh.

\section{Study Area- Uttar Pradesh}

Uttar Pradesh is between latitude $24^{\circ}-31^{\circ} \mathrm{N}$ and longitude $77^{\circ}-84^{\circ} \mathrm{E}$. Area wise, it is the fourth largest state of India. The Gangetic Plain occupies three quarters of the state. The entire state, except for the northern region, has a tropical monsoon climate. In the plains, January temperatures range from $12.5^{\circ} \mathrm{C}-17.5^{\circ} \mathrm{C}$ and May records $27.5^{\circ}-32.5^{\circ} \mathrm{C}$, with a maximum of $45^{\circ} \mathrm{C}$. Rainfall varies from $1,000-2,000 \mathrm{~mm}$ in the east to $600-1,000 \mathrm{~mm}$ in the west.

Uttar Pradesh is the most populous state in India. In the early 21 st century it had an overall population density of more than twice the national average. The Gangetic Plain supports the overwhelming majority of the state's population.

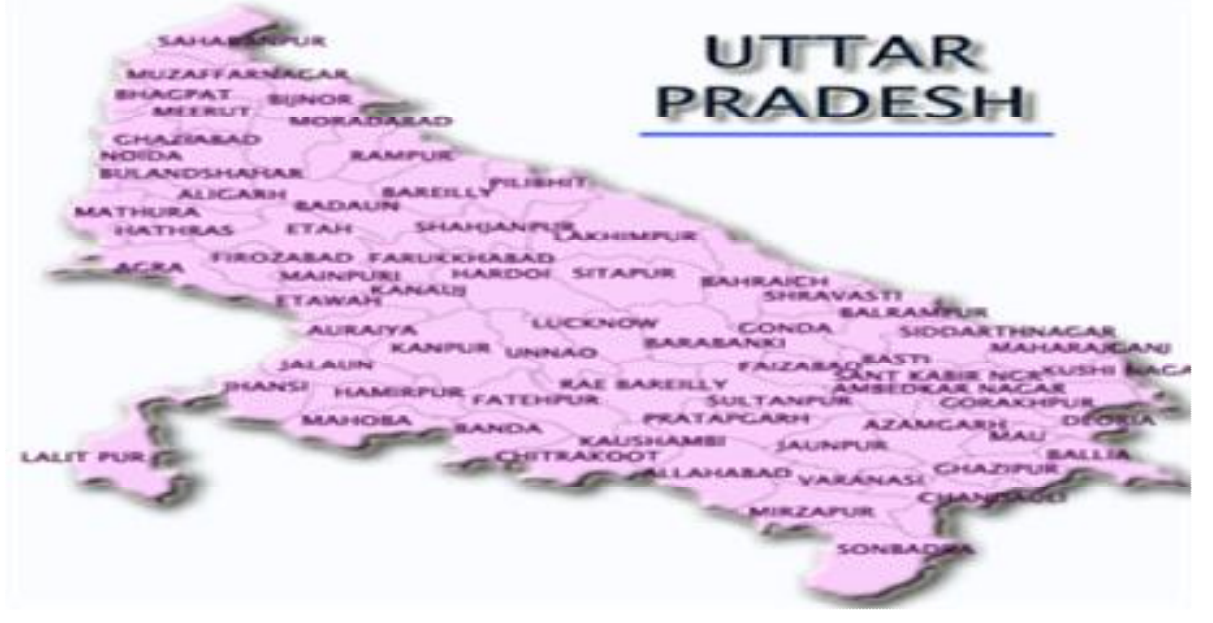


It has multicultural, multiracial, fabulous wealth of nature-hills, valleys, rivers, forests, and vast plains. Viewed as the largest tourist destination in India, Uttar Pradesh boasts of 35 million domestic tourists. More than half of the foreign tourists, who visit India every year, make it a point to visit this state of Taj and Ganga. Agra itself receives around one million foreign tourists a year coupled with around twenty million domestic tourists.

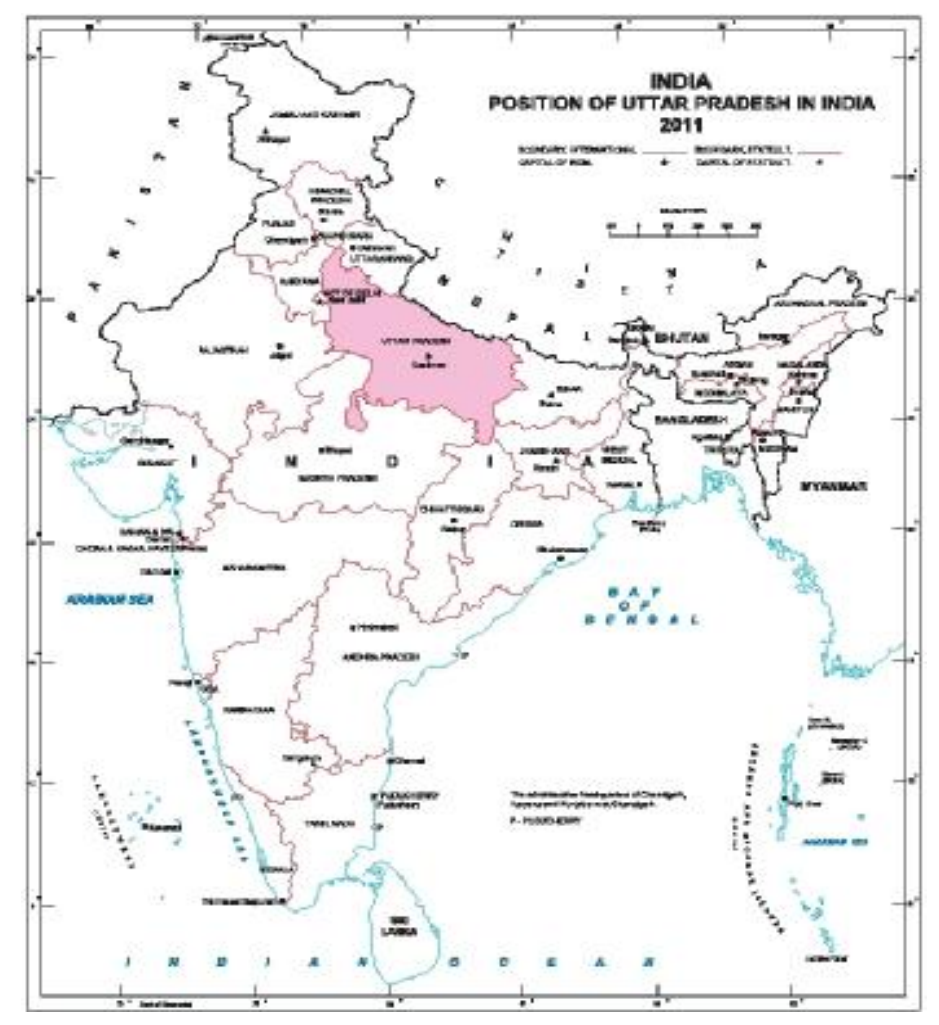

Uttar Pradesh is studded with places of tourist attractions across a wide spectrum of interest to people of diverse interests. The seventh most populated state of the world, Uttar Pradesh can lay claim to be the oldest seat of India's culture and civilization. It has been characterized as the cradle of Indian civilization and culture because it is around the Ganga that the ancient cities and towns sprang up. It has played the most important part in India's freedom struggle also.

\section{Methodology}

The present study aims to enquire into the expansion of female literacy in various districts of Uttar Pradesh. Secondary statistical data pertaining to female literacy (census 2011), obtained from the "Office of Registrar General and Census Commissioner of India (Delhi)", are mainly used in this study. The raw data obtained was analyzed and summarized to obtain meaningful information from it.

The raw data regarding total number of female literates of all 71 districts of Uttar Pradesh was converted into their corresponding literacy rates using the given formula:

\section{Female Literacy Rate $=\frac{\Sigma L_{t}}{\sum P_{t}} \times 100$}

Where,

$\sum L_{t}=$ total number of female literates excluding age group 0-6

$\sum P_{t=}$ total number of female population excluding age group 0-6

In order to analyze the status of female literacy in all 71 districts of Uttar Pradesh, the processed statistical data was plotted on the latest administrative map of state through "Monochromatic Colour Scheme".

\section{Analysis and Interpretation Of data}

The raw score of literate females was converted into percentage score which depicts the female literacy rates of various districts. During the tabulation of data two striking districts were observed with highest and lowest female literacy rates of $90.23 \%$ and $37.07 \%$ respectively and on its basis a categorization of total female literacy was made by constructing five categories of very high, high, average (medium), low and very low female literacy rates. For the convenient analysis the range of female literacy rate has been categorized as below.

$\checkmark$ Very high (65.51 to $81.42 \%)$

$\checkmark \operatorname{High}(60.51$ to $65.50 \%)$

$\checkmark$ Average (55.51 to $60.50 \%$ )

$\checkmark$ Low $(50.51$ to $55.50 \%)$

$\checkmark$ Very low (37.07 to $50.50 \%)$ 
Districtwise Female Literacy Rates (in \%)

\begin{tabular}{|c|c|c|c|c|c|}
\hline \multicolumn{3}{|c|}{ UTTAR PRADESH } & \multicolumn{3}{|c|}{59.26} \\
\hline SAHARANPUR & 63.30 & LALITPUR & 52.26 & MEERUT & 65.69 \\
\hline MUZAFFARNAGAR & 60.00 & HAMIRPUR & 57.19 & BAGHPAT & 61.22 \\
\hline BIJNOR & 61.45 & MAHOBA & 54.65 & GHAZIABAD & 81.42 \\
\hline MORADABAD & 49.63 & BANDA & 54.95 & GAUTAM BUDDHA NAGAR & 72.78 \\
\hline RAMPUR & 46.19 & CHITRAKOOT & 54.03 & BULANDSHAHAR & 56.60 \\
\hline FAIZABAD & 60.72 & FATEHPUR & 57.76 & KANSHIRAM NAGAR & 50.20 \\
\hline KANPUR DEHAT & 68.48 & ETAH & 61.72 & SIDDHARTHNAGAR & 49.61 \\
\hline MATHURA & 58.93 & BAHRAICH & 40.76 & PRATAPGARH & 60.99 \\
\hline AGRA & 59.16 & SHRAWASTI & 37.07 & KAUSHAMBI & 50.76 \\
\hline FIROZABAD & 64.80 & BALRAMPUR & 40.92 & ALLAHABAD & 62.67 \\
\hline MAINPURI & 68.35 & GONDA & 49.13 & BARABANKI & 54.10 \\
\hline BADAUN & 41.76 & ALIGARH & 57.48 & AMBEDKAR NAGAR & 64.62 \\
\hline BAREILLY & 50.35 & BASTI & 58.35 & SULTANPUR & 60.17 \\
\hline PILIBHIT & 52.43 & JHANSI & 64.88 & UNNAO & 58.54 \\
\hline SHAHJAHANPUR & 51.73 & MAHRAJGANJ & 50.14 & LUCKNOW & 73.88 \\
\hline KHERI & 52.62 & GORAKHPUR & 61.54 & RAE BARELI & 58.06 \\
\hline SITAPUR & 52.80 & KUSHINAGAR & 54.74 & FARRUKHABAD & 60.51 \\
\hline HARDOI & 59.17 & DEORIA & 61.34 & KANNAUJ & 64.46 \\
\hline BALLIA & 61.72 & AZAMGARH & 62.65 & ETAWAH & 71.16 \\
\hline JAUNPUR & 61.70 & MAU & 65.59 & AURAIYA & 71.97 \\
\hline GHAZIPUR & 62.29 & MIRZAPUR & 58.77 & MAHAMAYA NAGAR & 60.79 \\
\hline CHANDAULI & 63.07 & SONBHADRA & 54.11 & JYOTIBA PHULE NAGAR & 53.77 \\
\hline VARANASI & 68.20 & JALAUN & 63.88 & KANPUR NAGAR & 76.89 \\
\hline \multicolumn{3}{|c|}{ SANT RAVIDAS NAGAR(BHADOHI) } & 57.79 & SANT KABIR NAGAR & 56.99 \\
\hline
\end{tabular}

Source: Census of India 2011

\subsection{Very High Female Literacy Rate}

A High female literacy is a healthy phenomenon for the society and the state. The very high female literacy is categorized under the range of 65.51 to $81.42 \%$ and it was observed on the basis of data that there is very high regional variation in the female literacy throughout the study area.

The highest female literacy was found in the industrially advanced district of Ghaziabad recording $81.42 \%$ of literacy. Kanpur Nagar (76.89\%), Lucknow (73.88\%), Gautam Buddha Nagar (72.78\%), Auraiya (71.97\%), Etawah (71.16\%), Kanpur Dehat (68.48\%), Mainpuri (68.35\%), Varanasi (68.20\%), Meerut (65.69\%), and Mau (65.59\%) are the other districts followed by it. High economic growth and urban atmosphere are the major causes of very high female literacy in these districts.

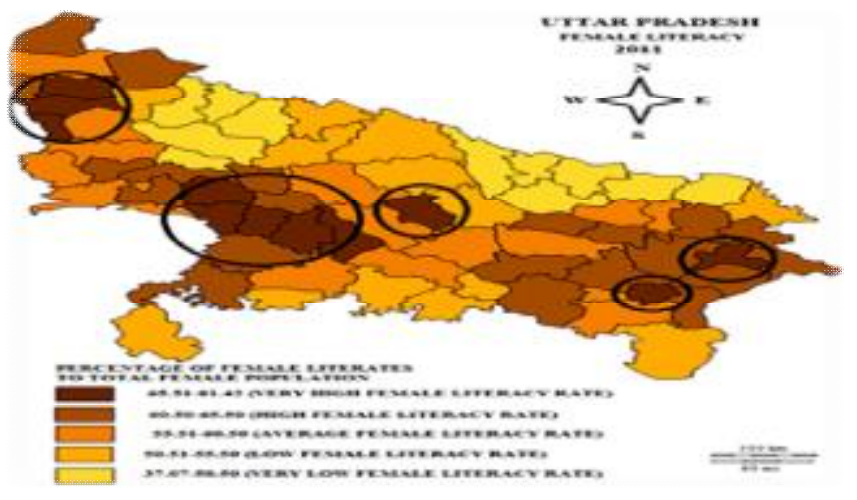




\subsection{High Female Literacy}

The districts said to be having a high female literacy are distinguished according to the range of 60.50 to $65.50 \%$. Most part of study area belongs to high female literacy covering about 21 districts itself. A patch of female literacy is formed in the eastern region by the districts of Faizabad, Ambedkar Nagar, Azamgarh, Gorakhpur, Deoria, Ballia, Pratapgarh, Jaunpur, Allahabad, Ghazipur and Chandauli.

A continuous range of districts with high female literacy is observed in the western part of state formed by the districts of Saharanpur, Bijnor, Baghpat, Mahamaya Nagar, Etah,

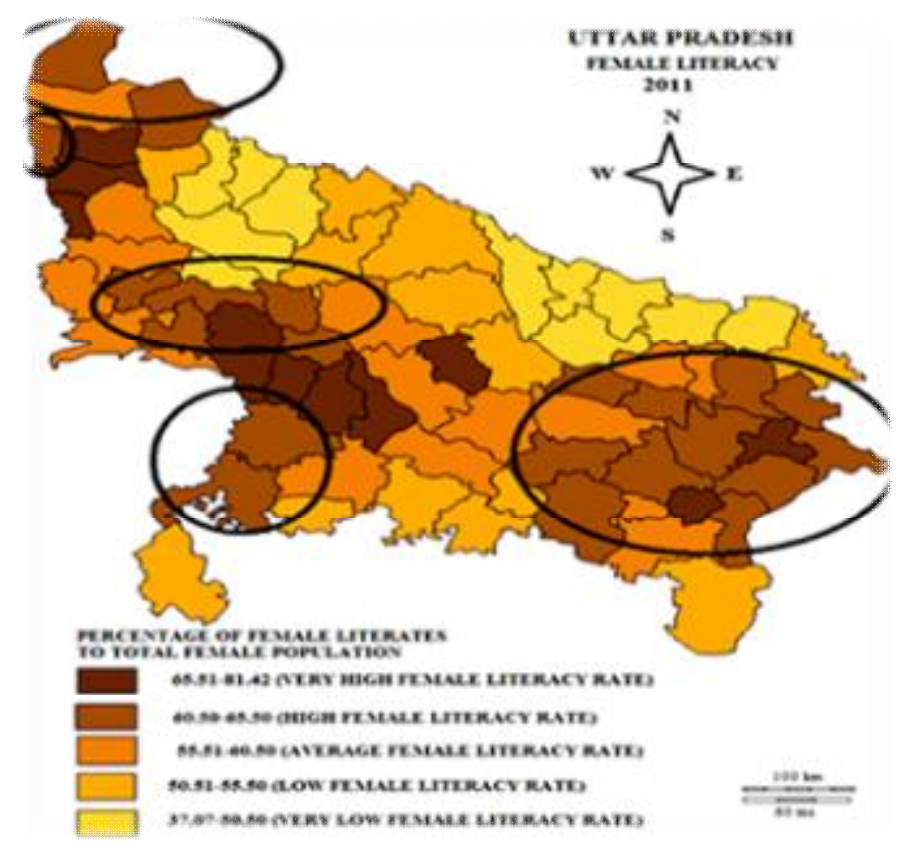

Firozabad, Farrukhabad, Kannauj, Jalaun, and Jhansi. All these districts are mostly located near the regions having very high female literacy. This shows that an urge and need for education is spread from the highly literate areas to the areas in lower hierarchy.

\subsection{Average Female Literacy}

A reasonable part of the study area belongs to medium level of female literacy which is experienced by the districts of Muzaffanagar, Bulandshahar, Aligarh, Mathura, and Agra in western region. Hardoi, Unnao, Rae Barely, and Sultanpur together form a belt in the central Uttar Pradesh. Hamirpur and Fatehpur in continuation represented average female literacy in the south western part of the state. Basti and Sant Kabir Nagar in the east while Sant Ravidas Nagar (Bhadohi) and Mirzapur in the south east region also come under average female literate regions. All the above districts possess the literacy rate in between 55.51 to $60.50 \%$. The average female literacy of the state also lies in this range i.e. of $59.26 \%$.

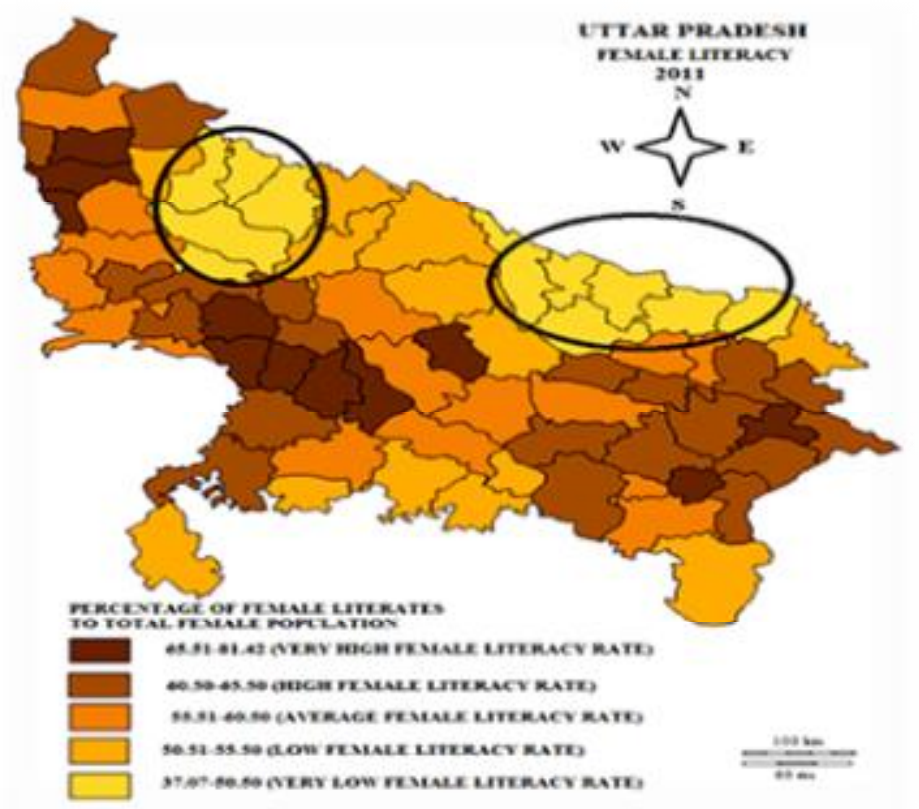




\subsection{Low Female Literacy}

Low female literacy is spread over the districts of Pilibhit, Kheri, Shahjahanpur, and Jyotibaphule nagar in the north and north western parts of state. Sitapur and Barabanki forming the central part of Uttar Pradesh are also included in this category.

Mahoba, Banda, Chitrakoot and Kaushambi lie in the southern part whereas districts of Kushinagar, Sonbhadra and Lalitpur suffering from low female literacy represents the north eastern, south eastern and south western extremes of the state respectively. All these districts lie in between 50.51 to $55.50 \%$ of female literacy rate.

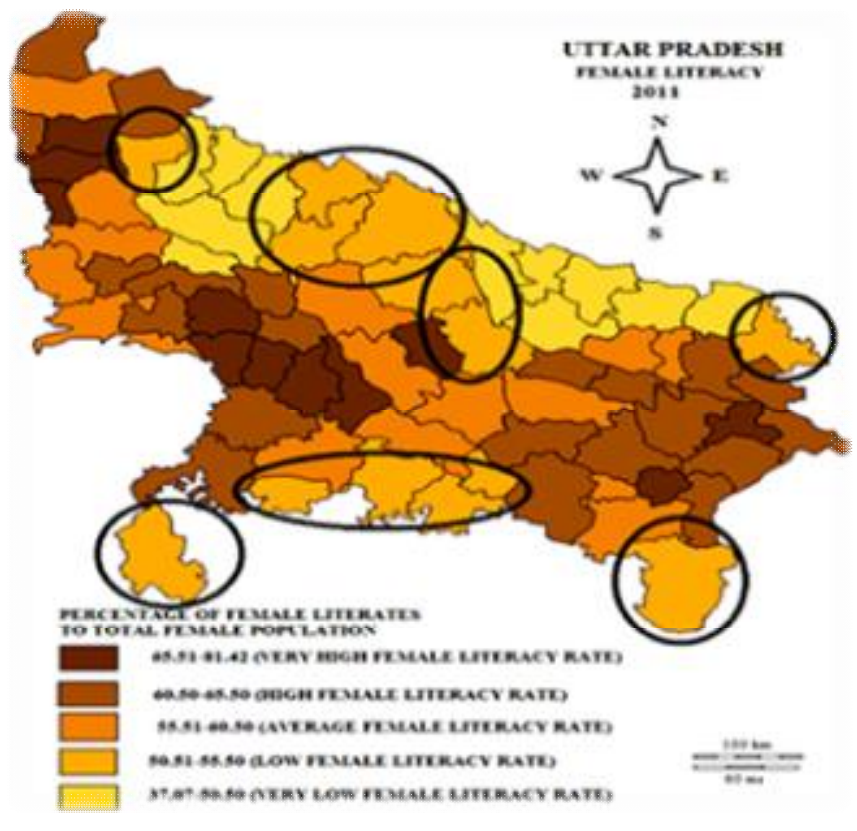

\subsection{Very Low Female Literacy}

As far as very low female literacy is concerned it is defined under the range of 37.07 to $50.50 \%$ and it was observed that two compact pockets are formed by the very low female literate districts.

One of the compact regions lies in the upper northern belt sharing the border of Uttarakhand formed by the districts of Moradabad, Rampur, Barelly, Badaun and Kanshiram Nagar. The other pocket also lies in the same belt sharing the Nepal border. These districts include Bahraich, Balrampur, Siddhartha Nagar, Maharajganj, and Gonda. Sharawasti, the district with lowest female literacy rate 0 f $37.07 \%$ also lays in this region. Economic backwardness and enlightenment towards education is the major cause of very low level of female literacy in these districts.

\section{Findings and Discussion}

7.1. The mean literacy rate of females in Uttar Pradesh is $59.26 \%$.

7.2. The highest literacy of females was traced in Ghaziabad district (81.42\%).

7.3. The lowest literacy of females was observed in the Shrawasti district (37.07\%).

7.4. $15.49 \%$ of districts in state possess a very high female literacy.

7.5. Almost $29.57 \%$ of districts are blessed with the high female literacy.

7.6. Average female literacy is observed in the $21.12 \%$ districts in the state.

7.7. $18.30 \%$ of districts in the state are exposed to the low female literacy status.

7.8. The percentage of districts suffering from the very low female literacy is also $15.49 \%$, equivalent to that of having very high female literacy.

The status of female literacy has shown a remarkable melioration in Uttar Pradesh over the last decade (2001-2011), according to the provisional Census data 2011. In actual, the rate of female literacy has been enhanced over by $59 \%$ with a jump of $17 \%$ as compared to $42 \%$ of female literacy rate during 2001 .

The study has unwrapped the literacy status of females in the state revealing Ghaziabad with highest literacy rate of $81.42 \%$ followed by the districts of Kanpur Nagar, Lucknow, Auraiya, Etawah, Kanpur Dehat, Mainpuri, Varanasi, Meerut and Mau.

Among the low female literacy areas Moradabad, Rampur, Bareilly, Badaun and Kanshiram Nagar forms a compact region in the northern Uttar Pradesh. Along with these Bahraich, Balrampur, Siddhartha Nagar, Maharajganj, Gonda and Sharawasti form a pocket sharing the Nepal border. Sharawasti was found to be having $37.07 \%$ female literacy rate which is lowest of all. 
A very high regional variation with a declining trend regarding the female literacy was observed throughout the study area.

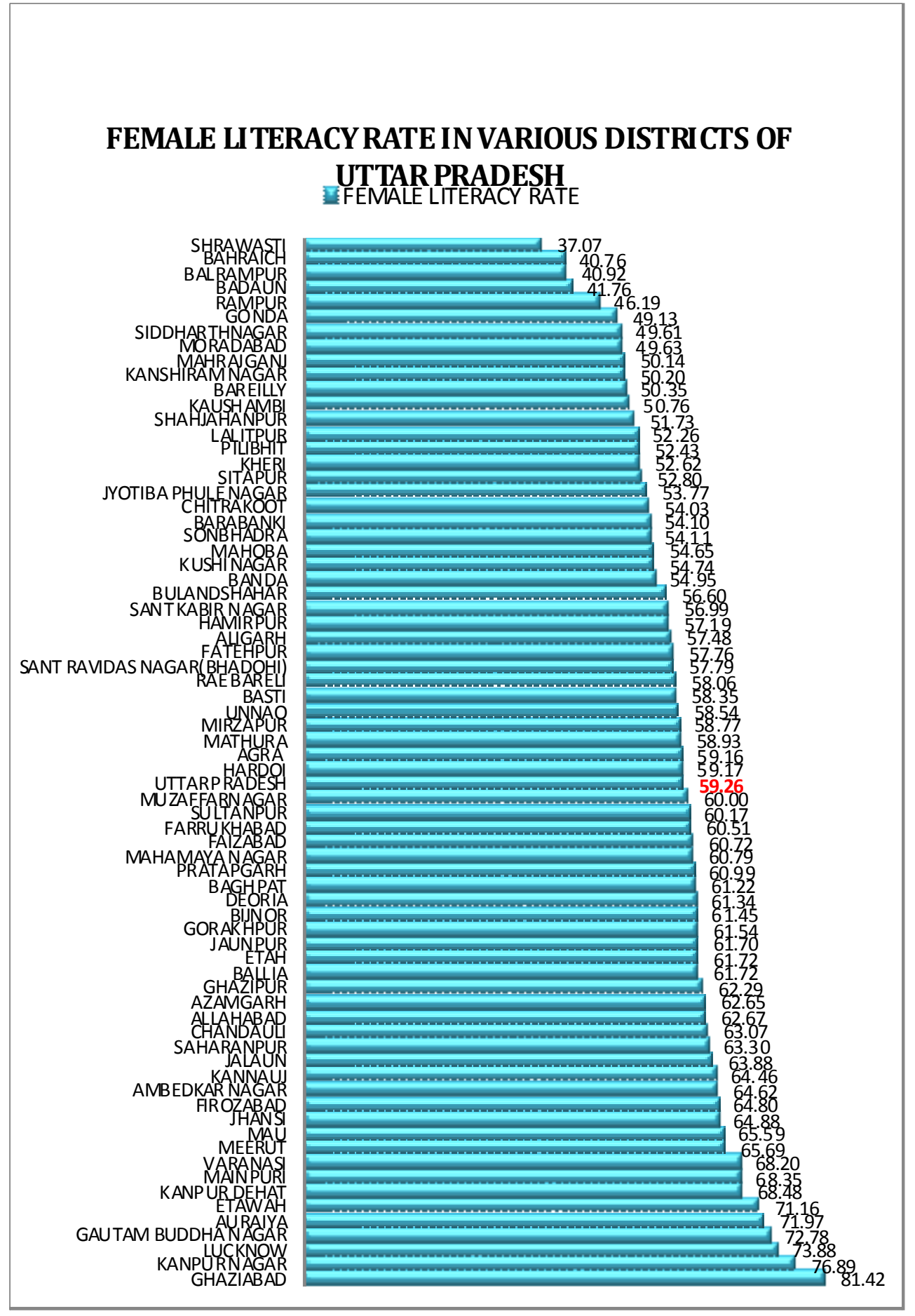

\section{References}

Best, J. W. (1963). Research in Education, New Delhi, Prentice Hall.

Bruke, F. (1983). Spatial disparities in the literacy of scheduled castes of Uttar Pradesh, paper presented at National Association of Geographers, India, 5th Annual Congress, Dec. 26-28, 1983, Aligarh.

Census of India (2011). provisional population totals, paper 1 Uttar Pradesh, series 10.

Mathur, B. B. (1988). Rural literacy in Uttar Pradesh: A Spatial Analysis, The Geographer, 35(2), July, 80-90

Singh, U. K. \& Singh, A. K. (2005). Level of literacy among the Tharus of Mihinpurwa block, Bahraich district (U.P), Geographical review of India,67(2), June, 188-194.

Tripathi, R. S. (1993). Impact of urbanization on literacy and concentration of non-agricultural workers in rural areas of Bundelkhand (Uttar Pradesh), Geographical review of India, 55(2), June 1993, 78-82.

Zaidi, A. N. (1986). Educational Planning and Regional Disparities in Education and Regional Development, Ed. By J.B.G. Tilak, Yatah Publication, 170-182. 